\title{
DEPENDENCE ANALYSIS OF ETHANOL, SUGAR, OIL, BRL/USD EXCHANGE RATE AND BOVESPA: A VINE COPULA APPROACH
}

\author{
Anderson Gomes Resende* \\ Osvaldo CANDido $^{\dagger}$
}

\begin{abstract}
Resumo
Este trabalho tem por objetivo analisar a relação de dependência entre o setor sucroalcooleiro (representado por Etanol e Açúcar), Petróleo, Taxa de Câmbio R \$/US\$ e o mercado acionário brasileiro (representado pelo índice BOVESPA). A metodologia utilizada é baseada em pair-cópulas e são comparadas três especificações: Regular Vine, a forma mais geral, e dois casos particulares Vine Canônico e Drawable vine. Os resultados obtidos indicaram relações de dependência alinhadas com a literatura existente, mas mostraram que estas relações se alteram significativamente quando a dependência condicional é levada em conta.
\end{abstract}

Palavras-chave: Commodities; Bio-combustíveis; Dependência multivariada; R-Vine cópulas.

\begin{abstract}
The aim of this study is to assess the dependence relationship of the sugarcane sector (represented by Ethanol and Sugar), Oil, BRL/USD Exchange Rate and Brazilian stock market (represented by the BOVESPA Bolsa de Valores de São Paulo - Index). Our methodology is based on paircopulas constructions, in which tree specification are compared: Regular Vine, more general, and two particular cases, Canonical vine (C-vine) and Drawable vine ( $\mathrm{D}$-vine). Primary results are shown to be aligned with the existing literature but they can change significantly when conditional dependence is taken into account.
\end{abstract}

Keywords: Commodities; Biofuels; Multivariate dependence; Regular-vine Copulas.

JEL classification: C46, C58, G10.

DOI: http://dx.doi.org/10.1590/1413-8050/ea 130174

\footnotetext{
${ }^{*}$ Centrais Elétricas do Norte do Brasil S.A. - Eletrobras Eletronorte. E-mail: andersonresende@gmail.com

† Graduate Program of Economics - Catholic University of Brasilia. E-mail: osvaldoc@ucb.br
} 


\section{Introduction}

In recent years interest regarding renewable fuels has increased around the world, mainly because of their potential of substituting fossil fuels. Some factors have contributed to consolidate these biofuels as a feasible substitute for fossil fuels: the increase of petroleum prices and the debate concerning global warming where the influence of $\mathrm{CO} 2$ emissions in this process plays an important role.

The production of biofuels, though still small, has increased steadily due to the adoption by many countries of goals for substituting part of their consumption of fossil fuels for renewable ones. The most consolidated initiatives nowadays, ethanol and biodiesel, which are planned to substitute gasoline and diesel oil, respectively, use mostly agro-commodities like corn, wheat, rye, sugar cane, soy and sunflower.

The investigation of how commodity prices interact with fuel prices is of utmost importance, but the conclusions regarding this process are not unanimous. There are those who advocate that biofuel production generates price distortions in the food market, while others state just the opposite. Mitchell (2008) highlights some difficulties in the comparison of different studies on that subject. According to him, the estimates can differ widely due to the different periods of time considered, different prices (export/import, wholesale, retail), and the focus given to different food products. Besides these, the analysis depends on the currency in which the prices are expressed, and if the increase of prices is adjusted by inflation (real) or not (nominal). Another point considered is that different methodologies probably lead to different results.

However, the understanding of how market prices of commodities (agricultural, fuel, currencies) related to each other, and how these prices influence and/or are influenced by other asset prices, such as stock market prices is very important for investors when they are setting portfolios and for producers and policy makers, when deciding about production and incentives policies. For example, considering that commodities are drilled, dug, produced and refined by companies with public traded stocks, the investors' decisions in the stock market can affect commodity prices and their availability throughout the economy. Also, commodity prices and availability can affect stock prices not only of commodity producing companies, but also of companies in other industries.

Therefore, this paper aims to assess the dependence relationship of the sugarcane market (sugar and ethanol prices), oil prices, the Brazilian Real to the USA Dollar (BRL/USD) exchange rate and the Brazilian Stock Exchange Index (Bolsa de Valores de São Paulo - BOVESPA index).

Several methodologies with different approaches have been used to study the dependence among the aforementioned variables in the literature; some of them consider the possibility of a nonlinear relationship. Balcombe \& Rapsomanikis (2008), using a sample for weekly Brazilian Real dominated prices for oil, ethanol and sugar in Brazil, from July 2000 to May 2006, estimate a Bayesian Error Correction Model (ECM) based on MCMC (a Bayesian Markov Chain Monte Carlo). The results suggest that oil prices are a long term determinant of sugar prices. They also conclude that the price adjustment process for sugar and ethanol in response to oil prices movement is nonlinear, while adjustment between sugar and ethanol is linear. But, the authors use a bivariate approach which may not adequately capture the joint effect of these 
variables.

Serra, Zilberman, Gil \& Goodwin (2011) model United States daily futures prices of corn, ethanol and oil for the period from July 21, 2005 to May 15, 2007 with a Smooth Transition Vector Error Correction Model (STVECM). The co-integration tests performed support the existence of a (single) long-term relationship between corn, ethanol, and oil prices. Their results also suggest regime changes on that relationship, especially from the strong rise in ethanol prices in mid-2006. From generalized impulse response functions the authors find that a shock in the oil and corn prices, when the system is far from its equilibrium, has an effect on ethanol prices in the same direction.

In addition to the previously mentioned studies, there is a huge amount of literature based on Vector Autoregression and Vector Error Correction (VAR/ VEC) analyzing prices interaction. Zhang et al. (2010) explore biofuel impact on global prices of agricultural commodities from a short- and long-term perspective. They use monthly prices for commodities, such as corn, rice, soybeans, sugar, and wheat along with ethanol fuel, gasoline, and oil prices from March 1989 to July 2008. The results indicate no direct relationship between long-term fuel prices and agricultural commodities prices, but concerning short term price movements, sugar prices affect all other agricultural commodities prices, except for rice.

Campos (2010) is another author that investigates the determinants of ethanol and sugar prices in a global context. More specifically, she analyses the impact of international ethanol, sugar, and oil prices on Brazilian (domestic) prices and the BRL/USD real exchange rate. It is concluded that the domestic sugar price can be significantly predicted by the international sugar price and by the BRL/USD real exchange rate and that ethanol is influenced by both domestic and international sugar prices.

There is another literature stream that takes into account the presence of conditional hetoroskedasticity in the price series and adds this to VAR/VEClike models. Serra, Zilberman \& Gil (2011), for instance, use the multivariate GARCH (Generalized Autoregressive Conditional Heteroscedasticity) model to investigate changes in price volatility and volatility spillovers in the ethanol industry. An interesting fact is that the authors estimate the co-integration relationship for the price series and the multivariate GARCH parameters jointly. They use weekly data series that range from July 2000 to February 2008 for crude oil international prices and Brazilian market prices for sugar and ethanol. The results indicate that oil and ethanol prices are positively related in the long run. Moreover, the empirical analysis suggests that oil prices not only affect the price levels of ethanol, but also their volatility. Thus, the volatility increase in the oil prices increases ethanol price volatility. Ethanol prices in turn have some impact on sugar prices, which leads to an indirect transmission of oil price volatility to sugar prices.

Zhang et al. (2009), apply the same combination VAR/VEC - Multivariate GARCH model for United States data that comprise weekly series of ethanol, corn, soybean, gasoline, and oil prices for the period from March 1989 to December 2007. Their results indicate that the gasoline prices directly affect ethanol and oil prices. Furthermore, the results also suggest that there is no long-run relationship among fuel prices (oil, ethanol, and gasoline) and agricultural commodities (corn and soybeans). Concerning the ethanol effects on corn and soybean prices, ethanol seems to influence the price level of longterm equilibrium of those commodities. Trujillo-Barrera et al. (2011) use daily 
prices for ethanol, corn and oil for the US market (from 2006 to 2011) and find that oil price volatility does influence ethanol and corn prices in opposition to that found by Zhang et al. (2010). According to the former authors, the effect of the crude oil price volatility on ethanol and corn price volatility is around $20 \%$, but in periods of great turbulence in the oil market, this effect can reach $50 \%$.

Another approach for the dependence analysis of random variables which has been widely used is the copula-based one. But there are just a few applications of copula-based models to assess the commodities-fuel-exchange rate relationship in the sense we have discussed so far. In Serra \& Gil (2012), for instance, an Error Correction copula-GARCH model is used to verify the biofuels ability to reduce fuel price fluctuations. The authors model the dependence between weekly prices of crude oil, biodiesel, and diesel in Spain from November 2006 to October 2010. The dependence parameters implied by Gaussian and Symmetrized Joe-Clayton (SJC) copulas are obtained for crude oil-biodiesel and crude oil-diesel separately. The results indicate that the dependence between crude oil and biodiesel is higher in the lower tail than in the upper tail, suggesting asymmetry to the left, while crude oil-diesel dependence tends to be symmetric. The authors conclude that biodiesel protects consumers against crude oil price increases and diesel does not. Similar results are found by Reboredo (2011) and Gregoire et al. (2008), also using copula modeling in the energy market. Nevertheless, these authors use bivariate copulas which cannot take into account the conditional dependence of all variables jointly. In this case, one may obtain misleading results.

Considering the discussion so far, the main goal of this work is to assess the dependence structure among sugar, ethanol, and oil prices, the Brazilian Real to USA Dollar (BRL/USD) exchange rate and the Brazilian Stock Exchange Index (Bolsa de Valores de São Paulo - BOVESPA index) jointly through Regular Vine Copulas.

Joe (1996) originally introduces a method for constructing multivariate distributions based on pair-copulas. Bedford \& Cooke $(2001,2002)$ propose the use of vine diagrams to organize these pair-copula decompositions. The method consists of decomposing a multivariate density in a cascade of bivariate copulas and their marginal densities. These Vine Copula models allow us to model the dependence structure among random variables in a more flexible and realistic way, since it is possible to specify joint distributions using copula functions that can be asymmetric and tailored, allowing for a wide range of nonlinear dependence without suffering the curse of dimensionality problems that arise when modeling data in high-dimensional spaces.

Despite having very interesting features, to be detailed later, vine copula models are still not widespread because of their recent development. Therefore, one of the main contributions of this work is the vine copula application, in which three specifications are considered: R-vine (Regular vine), the most general form, and two particular cases C-vine (Canonical vine) and D-vine (Drawable vine). This paper is divided into five sections besides this brief introduction. Section 2 describes pair-copula construction and its regular-vine representation along with some estimation and selection criteria issues. Section 3 shows the dataset and results for the empirical application. Lastly, some concluding remarks are presented. 


\section{Pair-copula model}

Sklar's Theorem states that every multivariate cumulative probability distribution function $F$ with marginals $F_{1}, \cdots, F_{n}$ may be written as

$$
F\left(x_{1}, \cdots, x_{n}\right)=C\left(F_{1}\left(x_{1}\right), F_{2}\left(x_{2}\right), \cdots, F_{n}\left(x_{n}\right)\right)
$$

In terms of the joint probability density function $f$, for an absolutely continuous $F$ with strictly increasing continuous margins $F_{1}, \cdots, F_{n}$, we have

$$
f\left(x_{1}, \cdots, x_{n}\right)=c_{12 \ldots n}\left(F_{1}\left(x_{1}\right), \cdots, F_{n}\left(x_{n}\right)\right) \cdot f_{1}\left(x_{1}\right) \cdots f_{n}\left(x_{n}\right)
$$

As highlighted in Aas et al. (2009), the joint probability density function $f$ can be factorized as

$$
f\left(x_{1}, \cdots, x_{n}\right)=f_{n}\left(x_{n}\right) \cdot f\left(x_{n-1} \mid x_{n}\right) \cdot f\left(x_{n-2} \mid x_{n-1}, x_{n}\right) \cdots f\left(x_{1} \mid x_{2}, \cdots, x_{n}\right)
$$

and each marginal conditional density can be written in terms of pair-copulas using

$$
f(x \mid \boldsymbol{v})=c_{x v_{j} \mid v_{-\mathbf{j}}}\left(F\left(x \mid \boldsymbol{v}_{-\mathbf{j}}\right), F\left(v_{j} \mid \boldsymbol{v}_{-\mathbf{j}}\right)\right) \cdot f\left(x \mid \boldsymbol{v}_{-\mathbf{j}}\right)
$$

for a vector $v$ with dimension $n$. Here $v_{j}$ is an arbitrarily chosen component of $v$ and $v_{-\mathrm{j}}$ corresponds to the vector $v$ excluding this component. It follows that the multivariate density function with dimension $n$ can be decomposed into its marginal densities and a set of bivariate copulas. The pair-copula decomposition involves marginal conditional distributions of the form $F(x \mid v)$. Joe (1996) showed that:

$$
F(x \mid v)=\frac{\partial C_{x, v_{j} \mid v_{-\mathbf{j}}}\left(F\left(x \mid v_{-\mathbf{j}}\right), F\left(v_{j} \mid v_{-\mathbf{j}}\right)\right)}{\partial F\left(v_{j} \mid v_{-\mathbf{j}}\right)}
$$

\subsection{Regular vine copulas}

This section presents and summarizes some results and definitions from Dissmann et al. (2013). An R-vine on $n$ elements is a nested set of $n-1$ trees such that the edges of tree $j$ become the nodes of tree $j+1$. The proximity condition insures that two nodes in tree $j+1$ are only connected by an edge if these nodes share a common node in tree $j$. We notice that the set of nodes in the first tree contains all indexes $1, \cdots, n$, while the set of edges is a set of $n-1$ pairs of those indexes. In the second tree the set of nodes contains sets of pairs of indexes and the set of edges is built of pairs of indexes, etc.

Formally, an R-vine structure is defined as (Bedford \& Cooke 2002)

Definition $1 R$-Vine Copula Specification $(F, V, B)$ is an $R$-vine copula specification if $F=\left(F_{1}, \ldots, F_{n}\right)$ is a vector of continuous invertible distribution functions, $V$ is an $n$-dimensional $R$-vine and $B=\left\{B_{e} \mid i=1, \ldots, i-1 ; e \in E_{i}\right\}$ is a set of copulae with $B_{e}$ being a bivariate copula, a so-called pair-copula.

A pdf related to the R-vine copula above is given by the product of conditional and unconditional copulas of each edge.

Theorem $\mathbf{1}$ Let $(F, V, B)$ be an R-vine copula specification on $n$ elements. There is a unique distribution $F$ that realizes this $R$-vine copula specification with density

$$
c\left(F_{1}\left(x_{1}\right), \cdots, F_{n}\left(x_{n}\right)\right)=\prod_{i=1}^{n-1} \prod_{e \in E_{i}} c_{j(e), k(e) \mid D(e)}\left(F\left(x_{j(e)} \mid x_{D(e)}\right), F\left(x_{k(e)} \mid x_{D(e)}\right)\right)
$$


where $x_{D(e)}$ is the sub-vector $x=\left(x_{1}, \cdots, x_{n}\right)$ indicated by the indexes in the variable $D_{(e)}$.

For C- and D-vines the density (6) can be rewritten in a more convenient way. As in Aas \& Berg (2009), and Brechmann \& Czado (2013), the canonical vine ( $\mathrm{C}$-vine) is a special case of the $\mathrm{R}$-vines class that contains a node with the maximum degree in each tree forming a star structure. In a canonical vine, there are $n-1$ hierarchical trees with increasing conditional sets and a key variable located at the root of the tree, and there are $n(n-1) / 2$ bivariate copulas.

The drawable vine (D-vine) consists of $n-1$ hierarchical trees, with path structures in their sequences and increasing conditional sets, and $n(n-1) / 2$ edges corresponding to each pair-copula.

\subsection{Pair-copula model: specification}

Dissmann et al. (2013) provides a complete inference procedure for pair-copula decomposition. The procedure consists of the following steps:

a) select an R-vine structure (i.e., unconditional and conditional pairs of variables);

b) select for each pair in a) a bivariate copula family (a pair-copula specification);

c) estimate all pair-copula parameters.

When modeling low-dimension specifications (e.g. 3 or 4 random variables), it is possible to estimate the parameters of all pairs in the decomposition and compare the resulting log-likelihood. However, in practice, this can become impossible for high-dimension problems.

Thus, following the Dissmann et al. (2013) procedure, in order to choose all pair-copulas and construct the vine structure, one must consider which bivariate relations are of most importance to model explicitly and let this determine which decomposition is to be used. The main purpose is to concentrate stronger dependences in the first trees, since these dependences are also the most important to model explicitly and precisely. Among the aforementioned three structures, the R-vine and the $\mathrm{D}$-vine are more flexible than the $\mathrm{C}$-vine, because the latter specifies relations between all variables and a key variable and the former one can freely choose which pair to model.

For each pair-copula, the empirical Kendall's tau $(\tau)$ is computed. It does not depend on distributional assumptions, being particularly useful in this case where different combinations of copula families are used. The empirical Kendall's tau is given by

$$
\tau_{T}=\frac{P_{T}-Q_{T}}{\left(\begin{array}{c}
T \\
2
\end{array}\right)}=\frac{4}{T(T-1)} P_{T}-1, \tau \in[-1,1],
$$

where $P_{T}$ and $Q_{T}$ are the number of concordant and discordant observation pairs respectively.

The empirical Kendall's tau is used as a criterion choice for the trees. The tree that is chosen is that which has the sum of the absolute value of all Kendall's tau, for the set of pair-copulas in each specific tree, maximized. 
Once the decomposition is chosen, the next step is to specify a parametric copula function, or family, for each pair-copula. The resulting multivariate joint distribution is valid if the copula family that best fits the data is chosen for each pair-copula. To choose the most appropriate copula family the Akaike Information Criterion (AIC) is used. The selection procedure consists in assigning an AIC value for each estimated copula function and then selecting that with the lowest AIC. This process is described in Brechmann \& Czado (2013). By using an independence test based on Kendall's tau, it is possible to specify the product (independence) copula for some pair-copulas. Taking into account that the Kendall's tau statistic is normal distributed ${ }^{1}$ with zero mean and variance $2(2 T+5) /(9 T(T-1))$, under the null hypothesis of independence, independence is rejected with significance of $5 \%$ if

$$
\sqrt{\frac{9 T(T-1)}{2(2 T+5)}}\left|\tau_{T}\right|>1,96
$$

Otherwise, if the test indicates independence for any pair-copula, there is no need to evaluate other copula families. One can choose the independence copula in this case.

\subsection{Estimation and inference}

After adequately choosing all pair-copulas and specifying their respective copula families it is possible to proceed to the estimation of the vine copula parameters by using the log-likelihood function associated to that. For the an $\mathrm{R}$-vine general specification the log-likelihood is

$$
\sum_{i=1}^{T} \sum_{l=1}^{n-1} \sum_{e \in E_{l}} \ln \left[c_{j(e), k(e) \mid D(e)}\left(F\left(u_{i, j(e)} \mid u_{i, D(e)}\right), F\left(u_{i, k(e) \mid D(e)} \mid u_{i, D(e)}\right) \mid \theta_{j(e), k(e) \mid D(e)}\right)\right] .
$$

Considering the fact that it is common to find tail dependence in financial returns, in addition to the theoretical Kendall's tau implied by the copula family, the upper, $\lambda_{U}$, and lower, $\lambda_{L}$, tail dependence coefficients are also computed when possible. The population version of Kendall's tau for $X$ and $Y$ is given by

$$
\begin{aligned}
\tau_{X, Y} & =P\left[\left(X_{1}-X_{2}\right)\left(Y_{1}-Y_{2}\right)>0\right]-P\left[\left(X_{1}-X_{2}\right)\left(Y_{1}-Y_{2}\right)<0\right] \\
& =4 \int_{0}^{1} \int_{0}^{1} C(u, v) d C(u, v)-1,
\end{aligned}
$$

where $C$ is the copula of $X$ and $Y$.

Concerning tail dependence coefficients, if a bivariate copula $C$ is such that $\lim _{u \rightarrow 1} \frac{1-2 u+C(u, u)}{1-u}=\lambda_{U}$ exists, then $C$ has upper tail dependence if $\lambda_{U} \in$ $(0,1]$. Similarly, if $C$ is such that $\lim _{u \rightarrow 0} \frac{C(u, u)}{u}=\lambda_{L}$ exists, then $C$ has lower tail dependence if $\lambda_{L} \in(0,1]$.

A tail dependence measure gives us the probability that both variables are located in the upper (or lower) tail of a joint distribution function. With this one can infer simultaneous extreme co-movements.

\footnotetext{
${ }^{1}$ See Genest \& Favre (2007) and Gregoire et al. (2008) for more details.
} 


\subsection{Choice among vine-copulas models}

In order to make comparisons among R-vine, $\mathrm{C}$-vine and $\mathrm{D}$-vine structures, the Vuong test is applied. Let $c_{1}$ and $c_{2}$ be two vine specifications to be compared in terms of their density functions with parameters $\theta_{1}$ and $\theta_{2}$. The standard sum, $v$, of the log-difference of punctual probabilities, $m_{i}=\log \left[\frac{c_{1}\left(u_{i} \mid \hat{\theta}_{1}\right)}{c_{2}\left(u_{i} \mid \hat{\theta}_{2}\right)}\right]$ for observations $u_{i} \in[0,1], i=1, \ldots, T$, is given by

$$
v=\frac{\frac{1}{n} \sum_{i=1}^{N} m_{i}}{\sqrt{\sum_{i=1}^{N}\left(m_{i}-\bar{m}\right)^{2}}} .
$$

Vuong (1989) shows that $v$ is asymptotically standard normal distributed. Defining the null hypothesis as $H_{0}: E\left[m_{i}\right]=0 \forall_{i}=1, \ldots, T$, the model $c_{1}$ is chosen instead of $c_{2}$ with significance $\alpha$ if $v>\Phi^{-1}\left(1-\frac{\alpha}{2}\right)$, where $\Phi^{-1}$ is the standard normal inverse. If $v<-\Phi^{-1}\left(1-\frac{\alpha}{2}\right)$, the Vuong test is inconclusive. Like the AIC and BIC criteria, the Vuong statistic can be corrected by the number of parameters in the model. There are two possibilities of correction, Akaike and Schwarz which correspond, respectively, to the penalty terms of AIC and BIC. Here the Vuong statistic calculated with no correction, AIC and BIC corrected.

\section{Results}

\subsection{Data}

For the empirical application we used weekly time series of the Ethanol anhydrous (eth) price in USD/Litre and Sugar (sug), USD/50kg price for Crystal sugar, (both from the Center of Advanced Studies on Applied Economics Luiz Queiroz College of Agriculture/University of São Paulo - CEPEA/ESALQ/USP) ${ }^{2}$; Oil (oil), Crude oil West Texas Intermediate (WTI) Cushing Oil Spot Price USD/BBL, the Brazilian Real to the US Dollar exchange rate (brus), provided by the Central Bank of Brazil (BCB), and BOVESPA index (bov), index of the Brazilian stock exchange (Bolsa de Valores de São Paulo- BM\& F/BOVESPA). The sample size has 639 data points and spans from July 13, 2000 to October 4, 2012.

The inclusion of the variable oil price when performing studies related to the biofuel market is justified, since it is the primary energy input in the world which competes with ethanol and biodiesel. Sugarcane is the main input used in ethanol production in Brazil, so including sugar prices is justified. From the producer point of view sugar can be replaced by ethanol as the final output, i.e., producers are able to choose to produce any combination of sugar or ethanol, including only one of them, using sugarcane.

Oil, sugar, and ethanol are internationally traded commodities, so the $\mathrm{BRL} / \mathrm{USD}$ exchange rate is of great importance for both Brazilian decision makers (producers and government) and investors around the world. And lastly, since financial markets are connected, the Brazilian stock market performance can play a role in affecting the aforementioned variables.

\footnotetext{
${ }^{2}$ Centro de Estudos de Economia Aplicada - Escola de Agricultura Luiz Queiroz (CEPEA/ESALQ/ USP).
} 
Table 1 shows the summary of statistics of log-returns for the five time series presented above. It can be seen that all series are far from being unconditionally normal distributed. Except for sugar, all series present positive excess of kurtosis, suggesting that their distributions are leptokurtic, i.e., they are heavy-tailed. The negative excess of kurtosis for sugar indicates its distribution has slender tails. Ethanol, oil, and BOVESPA have a negative asymmetry coefficient, which suggests that negative returns are more frequently observed than positive ones, while sugar and the BRL/USD exchange rate has a positive asymmetry coefficient.

Table 1: Summary of statistics

\begin{tabular}{lrrrrr}
\hline Variable & \multicolumn{1}{c}{ eth } & sug & \multicolumn{1}{c}{ oil } & \multicolumn{1}{c}{ brus } & \multicolumn{1}{c}{ bov } \\
\hline Mean & 0,00090 & 0,00112 & 0,00168 & 0,00018 & 0,00195 \\
Median & 0,00205 & 0,00110 & 0,00514 & $-0,00124$ & 0,00531 \\
Maximum & 0,24164 & 0,13906 & 0,30305 & 0,10957 & 0,16842 \\
Minimum & $-0,28174$ & $-0,20151$ & $-0,26199$ & $-0,14157$ & $-0,22324$ \\
Standard deviation & 0,04414 & 0,03963 & 0,05416 & 0,02309 & 0,04044 \\
Kurtosis & 4,93558 & 1,89175 & 3,71946 & 6,26386 & 3,19551 \\
Asymmetry & $-0,07771$ & 0,00197 & $-0,19145$ & 0,18459 & $-0,24927$ \\
\hline
\end{tabular}

The negative asymmetry of oil, ethanol, and BOVESPA can be explained by the $2007 / 2009$ sub-prime crisis period included in our sample, which has adversely impacted those returns. On one hand, oil and ethanol were affected by the decrease of the world demand and, on the other hand, foreign investors fled Brazil causing a decrease of the BOVESPA index and a depreciation of the Brazilian Real against the US dollar. This can explain the positive asymmetry of the BRL/USD exchange rate log-returns. Conversely, sugar prices have followed the great increase in agricultural commodity prices in the last years, explaining the greater frequency of positive returns for sugar in the sample.

\subsection{Modeling marginal distributions}

The margins $F_{1}, \cdots, F_{n}$ for the log-returns series in the empirical application , are modeled using an Autoregressive Moving Average, ARMA (P, d, Q), for the conditional mean, and a Generalized Autoregressive Conditional Heteroskedasticity, GARCH (p, q), for the conditional variance. The parameter $d$ is included to allow a fractionally integrated process in the conditional mean. Once a model for the marginal distributions is specified, the standardized residuals are taken to be used in the vine copula modeling.

To choose the appropriate order of the parameters $\mathrm{P}, \mathrm{Q}$ in the mean and $\mathrm{p}, \mathrm{q}$ in the variance the smallest integer that eliminates the autocorrelation in the standardized residuals and squared standardized residuals is used. In order to test for autocorrelation Ljung-Box Q statistic until lag 20 is used. The results for marginal distributions are presented in Table 2.

The results in Table 2 are those chosen among specifications with errors distributed as Standard Normal, Student- $\mathrm{t}$ with $v$ degree of freedom and Skewed$\mathrm{t}$ with $v$ degree of freedom and asymmetry $\lambda$ using log-likelihood ratio test and minimizing the AIC. The chosen models are: AR(2)-GARCH $(1,1)$-Student$\mathrm{t}$ for ethanol, AR(4)-GARCH(1,1)-Student-t for sugar, Constant-GARCH(1,1)- 
Table 2: Marginal modeling results

\begin{tabular}{|c|c|c|c|c|c|}
\hline & eth & sug & oil & brus & bov \\
\hline Constant & $\begin{array}{c}0,000803 \\
(0,6735)\end{array}$ & $\begin{array}{c}0,000517 \\
(0,7853)\end{array}$ & $\begin{array}{c}0,002776 \\
(0,1408)\end{array}$ & $\begin{array}{c}0,000518 \\
(0,749)\end{array}$ & $\begin{array}{c}0,002102 \\
(0,1467)\end{array}$ \\
\hline d-ARFIMA & - & - & - & $\begin{array}{c}0,134837^{* * *} \\
(0,0164)\end{array}$ & - \\
\hline $\operatorname{AR}(1)$ & $\begin{array}{c}0,266403^{* * *} \\
(0,000)\end{array}$ & $\begin{array}{c}0,377456^{* * *} \\
(0,000)\end{array}$ & - & $\begin{array}{c}-0,165821^{* *} \\
(0,0418)\end{array}$ & - \\
\hline $\operatorname{AR}(2)$ & $\begin{array}{c}0,100848^{* *} \\
(0,0111)\end{array}$ & $\begin{array}{c}0,131926^{* * *} \\
(0,0047)\end{array}$ & - & - & - \\
\hline $\operatorname{AR}(3)$ & - & $\begin{array}{c}0,025231 \\
(0,5691)\end{array}$ & - & - & - \\
\hline $\operatorname{AR}(4)$ & - & $\begin{array}{c}-0,083522^{* *} \\
(0,0273)\end{array}$ & - & - & - \\
\hline$\omega$ & $\begin{array}{c}1,111257 \\
(0,3115)\end{array}$ & $\begin{array}{c}1,242364^{* *} \\
(0,0107)\end{array}$ & $\begin{array}{c}1,817989^{* * *} \\
(0,0023)\end{array}$ & $\begin{array}{c}0,220073^{* *} \\
(0,0347)\end{array}$ & $\begin{array}{c}0,594516^{*} \\
(0,0517)\end{array}$ \\
\hline$\alpha_{i}$ & $\begin{array}{c}0,216009^{* *} \\
(0,0425)\end{array}$ & $\begin{array}{c}0,314442^{* * *} \\
(0,000)\end{array}$ & $\begin{array}{c}0,088228^{* * * *} \\
(0,0003)\end{array}$ & $\begin{array}{c}0,219238^{* * * *} \\
(0,0015)\end{array}$ & $\begin{array}{c}0,082946^{* * *} \\
(0,0007)\end{array}$ \\
\hline$\beta_{i}$ & $\begin{array}{c}0,765395^{* * *} \\
(0,0000)\end{array}$ & $\begin{array}{c}0,618541^{* * *} \\
(0,0000)\end{array}$ & $\begin{array}{c}0,840578^{* * *} \\
(0,0000)\end{array}$ & $\begin{array}{c}0,7572^{* * * *} \\
(0,0000)\end{array}$ & $\begin{array}{c}0,87977^{* * *} \\
(0,0000)\end{array}$ \\
\hline$v_{i}$ & - & - & $\begin{array}{c}9,519557^{* * *} \\
(0,0025)\end{array}$ & $\begin{array}{c}5,653420^{* * * *} \\
(0,000)\end{array}$ & $\begin{array}{c}10,821089^{* * *} \\
0,0119\end{array}$ \\
\hline$\lambda_{i}$ & - & - & $\begin{array}{c}-0,250815^{* * * *} \\
(0,0001)\end{array}$ & $\begin{array}{c}0,336824^{* * * *} \\
(0,0017)\end{array}$ & $\begin{array}{c}-0,259935^{* * *} \\
(0,000)\end{array}$ \\
\hline$Q(20)$ & $\begin{array}{c}19,9487 \\
(0,3357)\end{array}$ & $\begin{array}{c}22,0921 \\
(0,1402)\end{array}$ & $\begin{array}{c}17,6624 \\
(0,6096)\end{array}$ & $\begin{array}{c}27,0131 \\
(0,1043)\end{array}$ & $\begin{array}{c}22,0392 \\
(0,3383)\end{array}$ \\
\hline$Q^{2}(20)$ & $\begin{array}{c}15,4504 \\
(0,6308)\end{array}$ & $\begin{array}{c}16,2468 \\
(0,5753)\end{array}$ & $\begin{array}{l}11,474 \\
(0,8731)\end{array}$ & $\begin{array}{r}10,2231 \\
(0,9243)\end{array}$ & $\begin{array}{c}11,68 \\
(0,8633)\end{array}$ \\
\hline$A I C$ & $-3,755697$ & $-4,050045$ & $-3,196026$ & $-5,145204$ & $-3,732258$ \\
\hline$K S$ & 0,984228 & 0,942038 & 0,701932 & 0,983834 & 0,793718 \\
\hline$B E R K \quad 0,636946$ & 0,968043 & 0,605615 & 0,733342 & 0,458789 & \\
\hline
\end{tabular}

Note: $(* * *),(* *),(*)$ - significant at $1 \%, 5 \%, 10 \%$ respectively, p-value between brackets. $\omega, \alpha$ and $\beta$ are the $\operatorname{GARCH}(1,1)$ parameters. AIC (Akaike Information criterion). KS (Kolmogorov-Smirnov) and BERK (Berkowitz) are p-value for the uniform distributed test.

Skewed-t for oil, ARFIMA(1,d,0)-GARCH(1,1)-Skewed-t for the BRL/USD exchange rate and Constant-GARCH $(1,1)$-Skewed-t for BOVESPA.

By observing the series with standardized residuals Skewed-t distributed, one may see that their conditional distribution is still asymmetric, oil and BOVESPA with negative asymmetry and the BRL/USD exchange rate with positive asymmetry. (Asymmetry was previously indicated by the unconditional statistics in Table 1). Yet, by observing the BRL/USD exchange rate estimates, it can be seen that the parameter for fractional integration, $d$, is statistically significant. This means that this variable is characterized by a long range dependence process, since, i.e., the BRL/USD exchange rate has long memory.

Once we have obtained the standardized residuals, if the marginal distribution is well specified, their probability integral transformation (PIT) should be uniformly distributed in the interval $[0,1]-\mathrm{U}(0,1)$ distributed. This is a necessary result to identify the copulas in the vine copula modeling, the step of the estimation procedure. To test whether the PIT of the standardized residuals are $\mathrm{U}(0,1)$ distributed, the Berkowitz and Kolmogorov-Smirnov statistics are used as the goodness-of-fit test. Both tests, by looking at BERK and KS pvalues in Table 2, do not show evidence that the standardized residuals transformed are not $\mathrm{U}(0,1)$ distributed. Thus we can proceed to the vine copula modeling. 


\subsection{Modeling the joint distribution through vine copula}

In accordance to the procedure described in section 2.2, it is necessary to indicate and select the vine structure, i.e., specify the pair-copula structure so that the strongest pairs-dependence be in the first trees, which can be done using the Kendall's tau. Figure 1 shows the empirical Kendall's tau (lower part of the figure) and scatter plots (upper part of the figure) for each pair of transformed margins (PIT of the standardized residuals) modeled in section 3.2 .

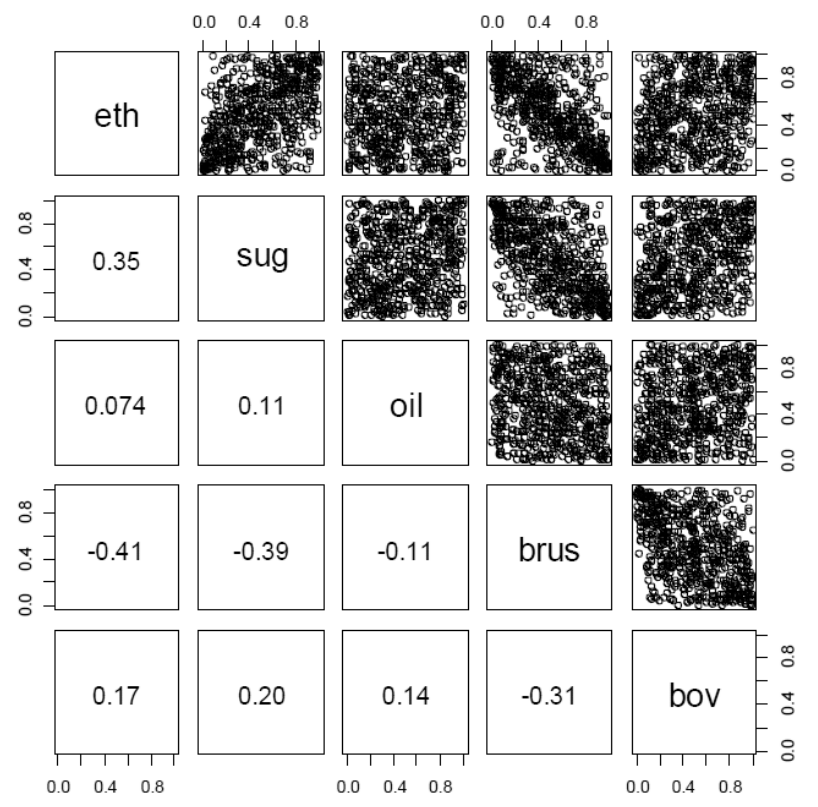

Figure 1: Kendall's tau and scatter plots

In order to adequately choose the vine structure for a given data set we have to decide which pair of variables are to be modeled and then specify the respective copula function. The process begins in the first tree that is formed by the pairs which maximize the sum of the absolute values of the Kendall's tau. Once the first tree is specified, the same is done for the second, the third, and so on until the vine structure specification is completed. After this, the next step is to choose the copula family for each pair-copula and estimate the parameters.

Eight different vine structures in our empirical application are estimated according to: (i) R-vine, C-vine or D-vine structure; (ii) independence test performed or not, and (iii) family used for the pair-copulas. All models are estimated using VineCopula R package (Schepsmeier et al. 2013). Thus, the estimated models are:

Mixed R-vine, Mixed C-vine and Mixed D-vine (with and without the independence test) - each bivariate copula is chosen among 31 families available in Schepsmeier et al. (2013). These can be symmetric or asymmetric families, having one or two parameters, allowing (or not) for tail dependence. 
R-vine (with and without the independence test) - each bivariate copula is chosen from elliptical family (Normal and Student-t).

Figure 2 shows the first tree for each estimated model. They are the same with and without the independence test and the families are also the same since in the first tree we always have the strongest bivariate dependences.

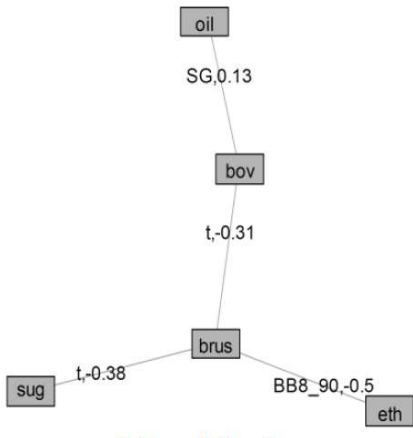

Mixed R-vine

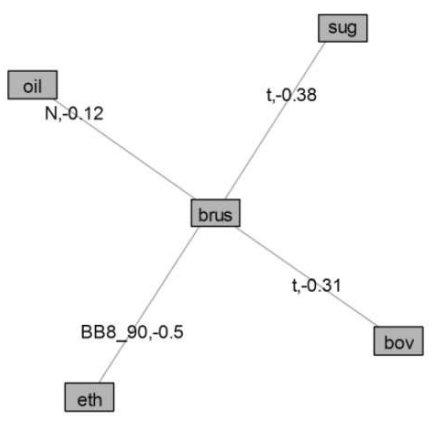

Mixed C-vine
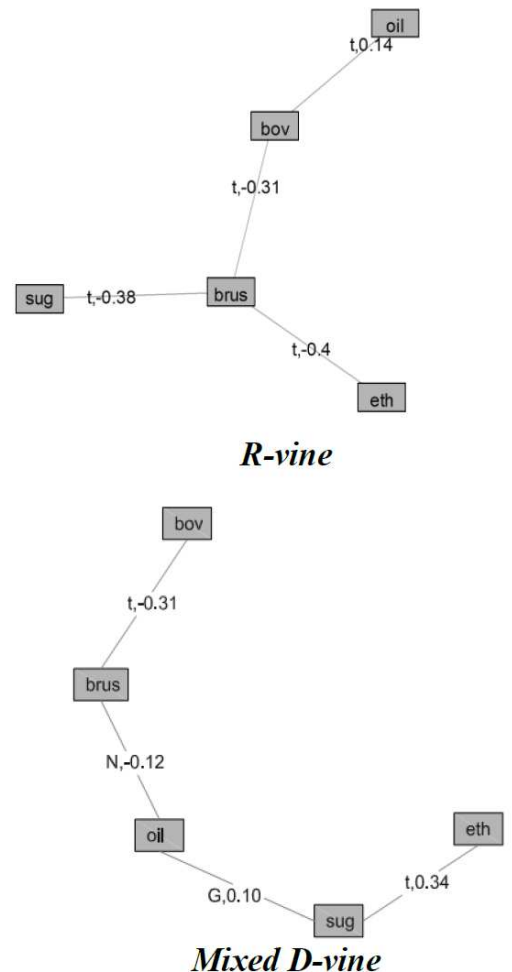

Figure 2: First tree of the estimated vine structure

The acronyms on each edge of the trees indicate the copula family used for that specific pair-copula while the number is the Kendall's tau implied by the respective copula family, e.g., in the Mixed R-vine first tree (upper-left corner of the figure 4) the copula family for the pair sugar-BRL/USD exchange rate (sug-brus) is a Student-t (t) copula with implied Kendall's tau of -0.38 (The acronyms can be identified by using Table 3 ).

It is noticeable from the first tree of the $\mathrm{R}$-vine and $\mathrm{C}$-vine specifications that the BRL/USD exchange rate has a main role in these structures, since the other variables have a strong dependence on it, as indicated by the Kendall's tau. One explanation for this behavior is that the ethanol, sugar, and oil prices are strongly influenced by the import/export dynamics. BOVESPA, in turn, is influenced by the BRL/USD exchange rate through stocks that comprise the index.

To start the comparison among the estimated models in Table 3, we can observe the copula families used and the number of times each of them appears in each vine structure, and also the number of parameters estimated in the complete structure. 


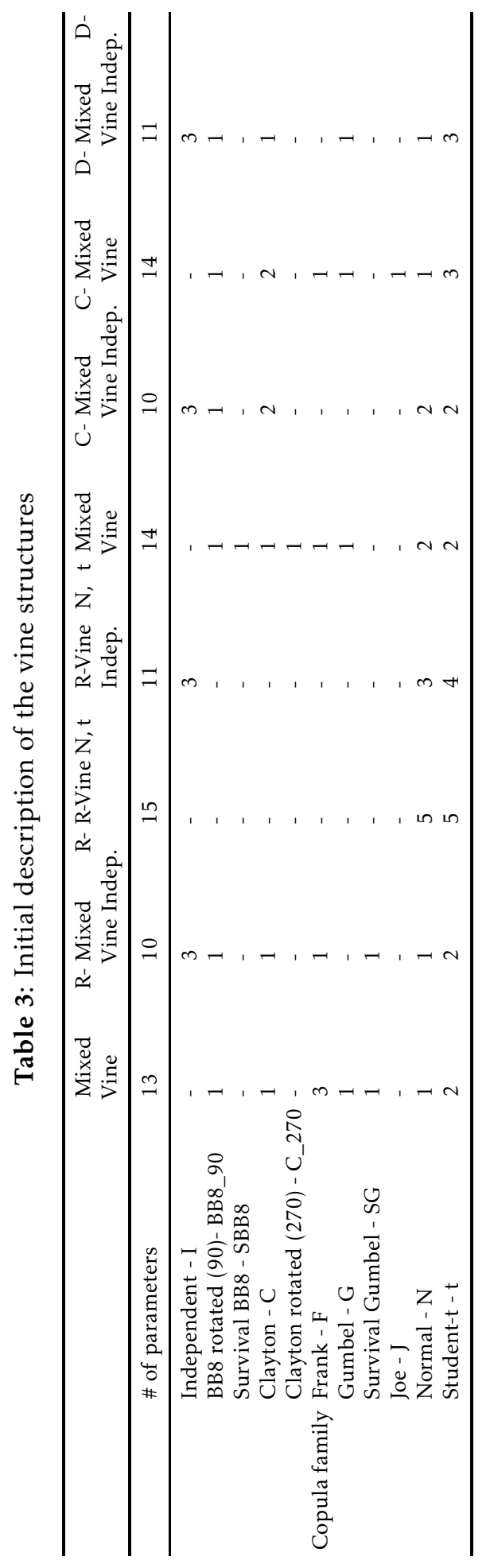


By using the independence test, ex ante, one can drastically reduce the number of parameters to be estimated when dealing with a large number of variables. Specifically in our case, the greatest reduction occurred in the Mixed C-vine, the model estimated after the independence test has 4 less parameters. The least reduction occurred in the Mixed D-vine and Mixed R-vine, 3 parameters less after the independence test.

In Table 4 the results for maximum log-likelihood value and the Vuong test for all estimated models are shown. Since the Vuong test is performed in pairs, we have fixed two benchmark models which are compared with all the other ones: Mixed R-vine (more general structure) and Mixed D-vine (the largest log-likelihood value, 383.68). The Voung test is performed considering a significance level $5 \%$.

From Table 4, the Vuong statistics with Akaike correction and no correction, taking Mixed R-vine as the benchmark model and comparing with the Mixed R-vine with independent terms, does not allow the indication of which one is the preferred model. However with Schwarz correction the test indicates the Mixed R-vine with independent terms as preferred. This can be explained by the weight assigned to the number of parameters in the Schwarz correction, since the benchmark model has 13 parameters, while the competing one has 7 . The Mixed D-vine with and without independent terms are indicated as preferred by the test; the latter by the three statistics and the former by the statistics with Akaike and Schwarz correction. For the other competing models, still taking Mixed R-vine as the benchmark, the Vuong test is inconclusive.

Taking the Mixed D-Vine as the benchmark model, it can be seen that the Mixed D-Vine is indicated as preferred to the Mixed R-vine and Mixed Cvine by all three statistics and also preferred to the Mixed R-vine and Mixed $\mathrm{C}$-vine, both with independent terms in accordance to the test with Akaike correction and no correction. For the other competing models the Vuong test is inconclusive.

Therefore, taking into account all the above results, it is possible to infer that the Mixed D-vine is the most indicated model for our dataset since it is indicated by the Vuong test and has the largest log-likelihood value. In spite of this, the results and some comments for all models are presented.

Table 5 presents the estimated parameters for the Mixed D-vine structure. Also shown are the Kendall's tau, the upper tail dependence $\left(\lambda_{U}\right)$ and lower tail dependence $\left(\lambda_{L}\right)$, when they exist.

Starting from the first tree of the Mixed D-vine model it can be noticed that there is unconditionally a negative dependence between BOVESPA and the BRL/USD exchange rate (bov,brus). The Kendall's tau implied by Student$t$ copula associated to this pair is -0.31 . The dependence between oil and the $\mathrm{BRL} / \mathrm{USD}$ exchange rate is also negative, and the copula for this pair is the Normal one with Kendall's tau of -0.12 , lower than that of BOVESPA and the $\mathrm{BRL} / \mathrm{USD}$ exchange rate.

The unconditional dependence between ethanol and sugar (eth,sug) is modeled by the Student-t copula that reveals a positive dependence, the Kendall's tau is 0.34 , with a symmetrical tail dependence coefficient of 0.08 . This result is compatible with those found in the literature presented previously (see Alves (2002) and Serra, Zilberman \& Gil (2011) for instance).

The only asymmetric copula of this first tree is for sugar/oil pair (sug,oil), represented by the Gumbel copula which is asymmetric to the right. The 


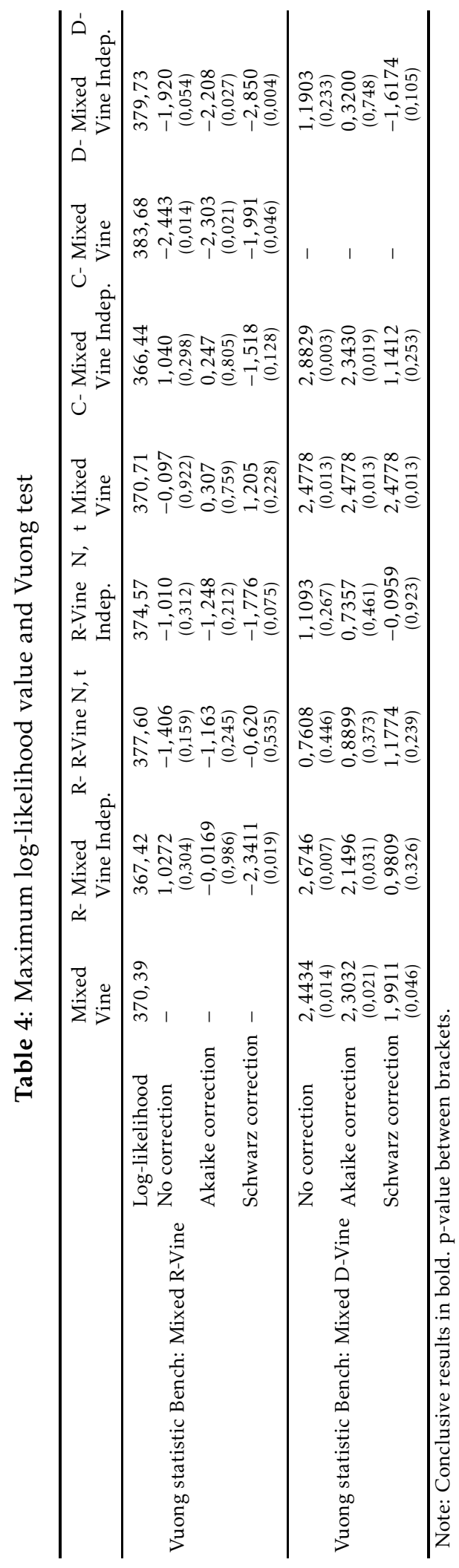


Table 5: Estimated parameters for the Mixed D-Vine model

\begin{tabular}{|c|c|c|c|c|c|c|c|}
\hline \multicolumn{2}{|c|}{ Tree Pair-copula } & \multirow{2}{*}{$\frac{\text { Copula }}{t}$} & \multirow{2}{*}{$\frac{\tau}{-0,314}$} & \multirow{2}{*}{$\begin{array}{c}\text { Par. 1 } \\
-0,474 \\
(0,030)\end{array}$} & \multirow{2}{*}{ 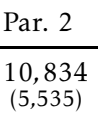 } & \multirow{2}{*}{$\frac{\lambda_{L}}{-}$} & \multirow{2}{*}{$\frac{\lambda_{U}}{-}$} \\
\hline & bov,brus & & & & & & \\
\hline \multirow[t]{3}{*}{1} & oil,brus & $N$ & $-0,117$ & $\begin{array}{c}-0,182 \\
(0,034)\end{array}$ & - & - & - \\
\hline & sug,oil & G & 0,100 & $\begin{array}{l}1,112 \\
(0,029)\end{array}$ & - & - & 0,135 \\
\hline & eth,sug & $t$ & 0,341 & $\begin{array}{l}0,511 \\
(0,027)\end{array}$ & $\begin{array}{c}10,163 \\
(3,800)\end{array}$ & 0,083 & 0,083 \\
\hline \multirow{3}{*}{2} & & $C$ & 0,088 & $\begin{array}{l}0,193 \\
(0,055)\end{array}$ & - & 0,028 & - \\
\hline & brus,sug|oil & $t$ & $-0,368$ & $\begin{array}{c}-0,546 \\
(0,026)\end{array}$ & $\begin{array}{l}9,602 \\
(4,320)\end{array}$ & - & - \\
\hline & oil,eth|sug & $J$ & 0,034 & $\begin{array}{l}1,061 \\
(0,027)\end{array}$ & - & - & 0,078 \\
\hline \multirow[t]{2}{*}{3} & \multicolumn{2}{|c|}{ bov,sug|brus, oil C } & 0,044 & $\begin{array}{l}0,091 \\
(0,049)\end{array}$ & - & 0,001 & 0,000 \\
\hline & \multicolumn{2}{|c|}{ eth,brus|sug,oil BB8_90 } & $-0,311$ & $\begin{array}{c}-5,802 \\
(3,378)\end{array}$ & $\begin{array}{c}-0,447 \\
(0,217)\end{array}$ & - & - \\
\hline 4 & \multicolumn{2}{|c|}{ bov,eth|brus.sug $F$} & $-0,005$ & $\begin{array}{c}-0,048 \\
(0,245)\end{array}$ & - & - & - \\
\hline
\end{tabular}

Note: Standard error between brackets.

Kendall's tau is 0.1 , suggesting a low dependence in the distribution as whole, and the upper tail dependence coefficient is 0.14 , which means that sugar and oil are more dependent in large positive returns (or gains).

In the second tree it is possible to assess conditional dependencies. Let us start with the pair-copula brus,sug|oil, i.e., the dependence between the BRL/USD exchange rate and sugar conditioned on oil. Student-t copula is the family in this case and the Kendall's tau is -0.37 . This means that, conditional on oil, the BRL/USD exchange rate and sugar are highly dependent. This result is as expected since Brazil is a big exporter of sugar and oil has a minor role in relation to the BRL/USD exchange rate and ethanol.

The dependence between BOVESPA and oil conditional on the BRL/USD exchange rate (bov,oil|brus) is characterized by the Clayton copula, asymmetric to the left, with overall dependence given by the Kendall's tau of 0.088 and lower tail dependence coefficient of 0.026 , which means that those variables are conditionally more dependent in large losses, or extreme negative returns. Thus, one can infer that, conditional on the BRL/USD exchange rate, the dependence between BOVESPA and oil is asymmetric to left, though low.

Conversely, conditional on sugar, the dependence relationship between oil and ethanol (oil,eth|sug) is low, the Kendall's tau is 0.03. But the Joe copula associated to this pair-copula is asymmetric to the right, whose upper tail dependence coefficient is 0.08 . This can indicate that oil and ethanol conditional to sugar is more dependent for extreme positive returns.

However, if we take a look at Table 6, which shows the estimated parameters for the Mixed D-vine with independent pair-copulas, specifically the second tree, it is noticeable that one of these independent pair-copulas is oil,eth|sug. Thus we cannot reject the hypothesis that, conditional on sugar, oil and ethanol are independent. This also can be seen in the third tree of all Cvine models and the fourth tree of all R-vine models, where the dependence 
between oil and ethanol, conditional on sugar, the BRL/USD exchange rate (oil,eth|sug,brus) and BOVESPA (oil,eth|bov,brus,sug) is not significant or the independence hypothesis is not rejected (Tables to and Appendix Tables to $13)^{3}$.

Table 6: Estimated parameters for the Mixed D-Vine model with independent terms

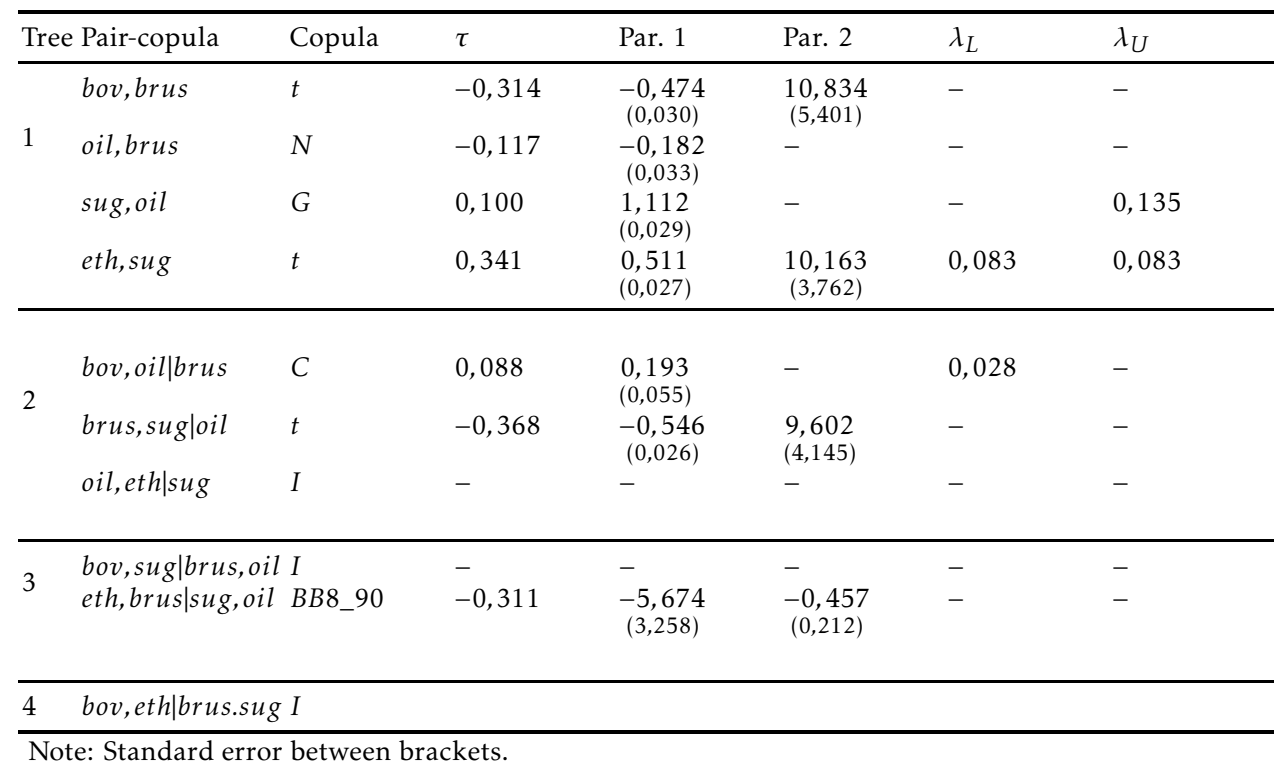

\section{Concluding remarks}

The main goal of this work is to assess the dependence relationship of the sugarcane sector, represented by the ethanol and sugar prices, oil prices, Brazilian real to US dollar exchange rate and the Brazilian stock market index, represented by the BMF/BOVESPA (Bolsa de Valores de São Paulo) index. To pursue this goal, we used weekly time series of log-returns of the aforementioned prices and index from July 13, 2000 to October 4, 2012, which comprise 639 data points. The methodological procedure is based on pair-copula constructions and their vine representations. Specifically, Regular vine (R-vine), Canonical vine (C-vine) and Drawable vine (D-vine) structures are estimated, capturing the dependence relationship of all five random variables.

For the marginal distributions, univariate ARMA-GARCH and ARFIMAGARCH models with Student-t or Skewed-t errors are used. Standardized residuals are obtained from them and then transformed into uniform $(0,1)$ distributed random variables using the probability integral transformation. By the Kolmogorov-Smirnov and Berkowitz tests, it cannot be rejected that the residuals transformed are uniformly distributed on $(0,1)$ interval. Therefore, they can be used to fit the vine copulas model.

Only the Brazilian Real to US Dollar exchange rate has supported a fractional integrated process in its conditional mean equation, indicating the pres-

\footnotetext{
${ }^{3}$ See the for additional results concerning non-selected vine-copula models.
} 
ence of long range dependence, or long memory. Once the marginal distributions are specified, the Mixed R-vine, D-vine and C-vine structures for the five-dimensional multivariate distribution are fitted, with and without independent pair-copulas. From the results of the joint distribution modeling it is possible to highlight the following:

- The Brazilian real to US dollar exchange rate has a central role in the dependence structure of the multivariate distribution under analysis, i.e., it has a strong negative dependence with the other variables, conditionally and unconditionally.

- Conditional on oil, the Kendall's tau measuring the dependence between sugar and exchange rate changes from -0.379 to -0.36 and for the ethanolexchange rate dependence, conditional on sugar and oil, the Kendall's tau is -0.311 .

- Ethanol and sugar have a strong positive dependence, Kendall's tau of 0.34 and symmetric tail dependence of 0.08 .

- Conditional on the Brazilian real to US dollar exchange rate, the pair BOVESPA-oil has a positive relationship (Kendall's tau is of 0.088 and lower tail dependence of 0.028).

- Oil seems to have low, or no effect on sugar. This may indicate that the positive relation between oil and sugar, commonly found in the literature, is a result of the exchange rate movement. The same can be said about the oil-ethanol relationship.

- Oil is the variable that has the lowest unconditional dependence with the Brazilian real to US dollar exchange rate, with Kendall's tau of 0.117.

These results seem to be in line with the Brazilian context. That is, the positive association between ethanol and sugar is related to the capacity of the producers to allocate sugarcane to the production of one to another, even with some technical constraint. Considering the fact that ethanol and sugar are commodities, and the biggest producers are exporters, the strong dependence of these variables with the Brazilian real to US dollar exchange rate is explained.

\section{Some pitfalls and further research}

An important point that is always considered in (vine) copula-based multivariate models is its flexibility in allowing the researcher to specify models for the marginal distributions and the dependence structure (the joint distributions among random variables), separately. This method, Inference Function for Margins (IFM), proposed by Joe and Xu (1996) is asymptotically normal, consistent, and asymptotically convergent to the full Maximum Likelihood Estimator (MLE). Choosing the IFM estimator often reduces the computational complexity of estimating multivariate models. Since there is no evidence of misspecification in the marginal modeling and given the static feature of the dependence parameters in our vine copula models, the use of the IFM estimator is supported, regardless the uncertainty concerning the joint estimation of the parameters, which, in these circumstances, is minimized. 
Some other issues should be taken into account: (1) the time span of the data includes the 2008 Worldwide Financial Crisis. Although the timevarying characteristics of the marginal modeling, i.e., time-varying conditional volatilities, capture the impact of the crisis on the individual prices volatilities, the joint dependence parameters do not. This could lead to over- or underestimated vine-copula parameters. (2) One could question the use of constant copula (dependence) parameters over time (static). Letting parameters evolve over time is a concern for some researchers of Regular Vine Copula modeling. But one must take into account the many issues that arise from making vine copula parameters time-varying, most of them technical issues. First, a time process needs to be specified. Patton (2006) and Silva Filho et al. (2012) model the copula parameters varying through time according to an evolution equation in a bivariate context, which can be extended to a vine context. Second, a two-step IFM estimator may no longer be implemented and only a sequential estimation for the vine parameters can be performed. Those issues imply a greater number of parameters to be estimated and, in general, a less efficient multi-step estimator will be implemented, which exacerbates the uncertainty concerning the joint estimation of the parameters. To deal with this problem a bootstrap-based estimator for the covariance matrix should be used.

A first direction for further research is to find an appropriate specification for the time evolution of the copula parameters and test whether the dependence among ethanol, sugar prices, oil prices, the Brazilian real to US dollar exchange rate, and the Brazilian stock market index is static or dynamic.

A second direction is to increase the number of variables in order to consider not only the stock market index but also the stock prices of companies directly related to commodity production, and add substitute commodities for ethanol and sugar.

Those extensions can bring some new empirical insights on the dependence among commodities, currencies and stock markets.

\section{Acknowledgments}

The authors gratefully acknowledges the financial support of CNPq (406568/ 2012-0 and 453993/2014-1).

\section{Bibliography}

Aas, K. \& Berg, D. (2009), 'Models for construction of multivariate dependence - a comparison study', The European Journal of Finance 15(7-8), 639659.

URL: $h t t p: / / d x . d o i . o r g / 10.1080 / 13518470802588767$

Aas, K., Czado, C., Frigessi, A. \& Bakken, H. (2009), 'Pair-copula constructions of multiple dependence', Insurance: Mathematics and Economics 44(2), $182-198$.

URL: $h t t p: / / w w w . s c i e n c e d i r e c t . c o m / s c i e n c e / a r t i c l e / p i i / S 0167668707000194$

Alves, L. R. A. (2002), Transmissao de precos entre produtos do setor sucroalcooleiro do estado de sao paulo, Master's thesis, Escola Superior de Agricultura Luiz de Queiroz, Piracicaba. 
Balcombe, K. \& Rapsomanikis, G. (2008), 'Bayesian estimation and selection of nonlinear vector error correction models: The case of the sugar-ethanol-oil nexus in brazil', American Journal of Agricultural Economics 90(3), 658-668. URL: http://www.jstor.org/stable/20492320

Bedford, T. \& Cooke, R. M. (2001), 'Probability density decomposition for conditionally dependent random variables modeled by vines', Annals of Mathematics and Artificial Intelligence 32(1-4), 245-268.

URL: $h t t p: / / d x$.doi.org/10.1023/A\%3A1016725902970

Bedford, T. \& Cooke, R. M. (2002), 'Vines-a new graphical model for dependent random variables', Ann. Statist. 30(4), 1031-1068.

URL: $h t t p: / / d x$.doi.org/10.1214/aos/1031689016

Brechmann, E. \& Czado, C. (2013), 'Risk management with highdimensional vine copulas: An analysis of the euro stoxx 50', Statistics $\mathcal{E}$ Risk Modeling 30(4), 307-342.

Campos, S. K. (2010), Fundamentos econômicos da formação do preço internacional de açúcar e dos preços domésticos de açúcar e etanol, $\mathrm{PhD}$ thesis, Escola Superior de Agricultura Luiz de Queiroz, Piracicaba.

Dissmann, J., Brechmann, E., Czado, C. \& Kurowicka, D. (2013), 'Selecting and estimating regular vine copulae and application to financial returns', Computational Statistics \& Data Analysis 59(0), 52 - 69.

URL: http://www.sciencedirect.com/science/article/pii/S0167947312003131

Genest, C. \& Favre, A. (2007), 'Everything you always wanted to know about copula modeling but were afraid to ask', Journal of Hydrologic Engineering 12(4), 347-368.

URL: $h t t p: / / d x . d o i . o r g / 10.1061 /(A S C E) 1084-0699(2007) 12: 4(347)$

Gregoire, V., Genest, C. \& Gendron, M. (2008), 'Using copulas to model price dependence in energy markets', Energy Risk pp. 62-68.

Joe, H. (1996), Families of m-variate distributions with given margins and $\mathrm{m}(\mathrm{m}-1) / 2$ bivariate dependence parameters, in L. Rueschendorf, B. Schweizer \& M. Taylor, eds, 'In Distributions with Fixed Marginals and Related Topics', IMS Lecture Notes-Monograph Series, Hayward, CA., pp. 120 141.

Mitchell, D. (2008), A Note On Rising Food Prices, The World Bank.

URL: http://elibrary.worldbank.org/doi/abs/10.1596/1813-9450-4682

Patton, A. J. (2006), 'Modelling asymmetric exchange rate dependence', International Economic Review 47(2), 527-556.

URL: $h t t p: / / d x . d o i . o r g / 10.1111 / j .1468-2354.2006 .00387 . x$

Reboredo, J. C. (2011), 'How do crude oil prices co-move?: A copula approach', Energy Economics 33(5), 948 - 955.

URL: http://www.sciencedirect.com/science/article/pii/S0140988311000892

Schepsmeier, U., Stoeber, J. \& Brechmann, E. C. (2013), 'Statistical inference of vine copulas vinecopula r package'. 
Serra, T. \& Gil, J. M. (2012), 'Biodiesel as a motor fuel price stabilization mechanism', Energy Policy 50(0), 689 - 698. <ce:title $>$ Special Section: Past and Prospective Energy Transitions - Insights from History</ce:title>.

URL: http://www.sciencedirect.com/science/article/pii/S0301421512006726

Serra, T., Zilberman, D. \& Gil, J. M. (2011), 'Price volatility in ethanol markets', European Review of Agricultural Economics 38(2), 259-280.

URL: $h t t p: / / e r a e . o x f o r d j o u r n a l s . o r g / c o n t e n t / 38 / 2 / 259$.abstract

Serra, T., Zilberman, D., Gil, J. M. \& Goodwin, B. K. (2011), Nonlinearities in the us corn-ethanol-oil price system, 2008 Annual Meeting, July 27-29, 2008, Orlando, Florida 6512, American Agricultural Economics Association (New Name 2008: Agricultural and Applied Economics Association).

URL: $h t t p: / / i d e a s . r e p e c . o r g / p / a g s / a a e a 08 / 6512 . h t m l$

Silva Filho, O. C., Ziegelmann, F. A. \& Dueker, M. J. (2012), 'Modeling dependence dynamics through copulas with regime switching', Insurance: Mathematics and Economics 50(3), 346 - 356.

URL: $h t t p: / / w w w . s c i e n c e d i r e c t . c o m / s c i e n c e / a r t i c l e / p i i / S 0167668712000029$

Trujillo-Barrera, A., Mallory, M. \& Garcia, P. (2011), Volatility spillovers in the u.s. crude oil, corn, and ethanol markets, in 'In: NCCC-134 Conference on Applied Commodity Price Analysis, Forecasting, and Market Risk Management', St. Louis, Missouri.

Vuong, Q. H. (1989), 'Likelihood ratio tests for model selection and nonnested hypotheses', Econometrica 57(2), pp. 307-333.

URL: $h t t p: / / w w w . j s t o r . o r g / s t a b l e / 1912557$

Zhang, Z., Lohr, L., Escalante, C. \& Wetzstein, M. (2009), 'Ethanol, corn, and soybean price relations in a volatile vehicle-fuels market', Energies 2(2), 320. URL: $h t t p: / / w w w . m d p i . c o m / 1996-1073 / 2 / 2 / 320$

Zhang, Z., Lohr, L., Escalante, C. \& Wetzstein, M. (2010), 'Food versus fuel: What do prices tell us?', Energy Policy 38(1), 445 - 451.

URL: http://www.sciencedirect.com/science/article/pii/S0301421509007174

\section{Appendix A Other estimated models results}

It is worthy to observe the results for the Mixed R-vine in Table A.1 and Mixed $\mathrm{C}$-vine in Table A.2. In the Mixed R-vine the pair-copula oil,bov shows up in the first tree, which corresponds to the unconditional dependence between oil and BOVESPA modeled by the Survival Gumbel copula family with Kendall's tau and lower tail dependence of 0.13 and 0.17 , respectively. This positive relation can be explained by the fact that PETROBRAS (Petroleum Brazil), the 7th biggest energy company in the world, has the greatest participation in the BOVESPA index (8.17\% for PTR 4 and $2.66 \%$ for PTR3 in June 2013), OGX Petroleum has the fourth greatest participation (3.85\% for OGXP3), besides some other corporations who depend directly on oil and have participation on the BOVESPA index.

Note also the pair-copula bov,oil|sug,brus in the third tree of the Mixed C-vine model and Mixed C-vine with independent pair-copulas (Table A.3). 
Conditional on sugar and the BRL/USD exchange rate, the dependence between oil and BOVESPA is still positive, Kendall's tau of 0.098 implied by SBB8 copula (Mixed C-vine) and of 0.087 with lower tail dependence of 0.026 implied by the Clayton copula (Mixed C-vine with independent pair-copulas). Remember that the dependence between BOVESPA and oil conditional on the $\mathrm{BRL} / \mathrm{USD}$ exchange rate (bov,oil|brus) is characterized by the Clayton copula with Kendall's tau of 0.088 and lower tail dependence coefficient of 0.026 . Thus, we can conclude that the addition of sugar as a conditioning variable in the pair-copula bov,oil|brus seems to have no impact on the conditional dependence of BOVESPA and oil.

The pair-copula eth,brus has appeared in both Mixed R-vine and Mixed C-vine models (first tree) with Kendall's tau of -0.42 , indicating a strong negative unconditional dependence between ethanol and the BRL/USD exchange rate. The same can be said of the unconditional dependence between sugar and the BRL/USD exchange rate (sug,brus), whose Kendall's tau is -0.379 . Conditional on oil, the dependence between sugar and BRL/USD exchange rate (sug,brus|oil) does not seem to be change significantly. In this case the Kendall's tau is -0.368 .

Considering the dependence between ethanol and sugar conditional on the BRL/USD exchange rate (eth,sug|brus), in the second tree, the Kendall's tau of 0.19 is noteworthy. The unconditional dependence between these variables is 0.34 (first tree of the Mixed D-vine model - Table 5) and the associated copula is Student-t, with tail dependence coefficient of 0.08 . Conditional on the BRL/USD exchange rate the copula is Normal, with no tail dependence. It is worth noting that both ethanol and sugar are highly related to the BRL/USD exchange rate and highly dependent on each other unconditionally, though, conditional on the BRL/USD exchange rate the dependence between ethanol and sugar is still high.

Conversely, one can compare the unconditional dependence between oil and sugar (sug,oil - first tree of the Mixed D-vine model in Table 5) with that conditional on the BRL/USD exchange rate in the second tree of the Mixed C-vine (oil,sug|brus - Table A.2). For both pair-copulas the related family is the Gumbel copula, but for the conditional case the dependence is less than half of the unconditional one. More precisely, the Kendall's tau is 0.1 and the upper tail dependence is 0.13 for the unconditional relation and is 0.04 and 0.06 respectively, in the conditional case. Thus, it can be concluded that the dependence between oil and sugar is low and gets even lower when considered conditional on the BRL/USD exchange rate, if in the Mixed C-vine with independent terms (Table A.3), the independence hypothesis is not rejected for the pair-copula oil,sug|brus. When conditional on the BRL/USD exchange rate and BOVESPA, the independence hypothesis is also not rejected for the $\mathrm{R}$-vine with independent terms (Tables and ).

The dependence between BOVESPA and ethanol appears only in the conditional form in the third tree of the R-vine specifications, conditional on sugar and the BRL/USD exchange rate, and in the fourth tree of all D-vine and Cvine structures, conditional on all other variables. Those trees are the last ones of the five variable vine structures so with the weakest dependence, since is kept the strongest dependence in the first tree. The results in this case are not significant and is not rejected the conditional independence hypothesis between BOVESPA and ethanol. Similarly, BOVESPA and sugar conditional relation cannot be rejected of being independent. 


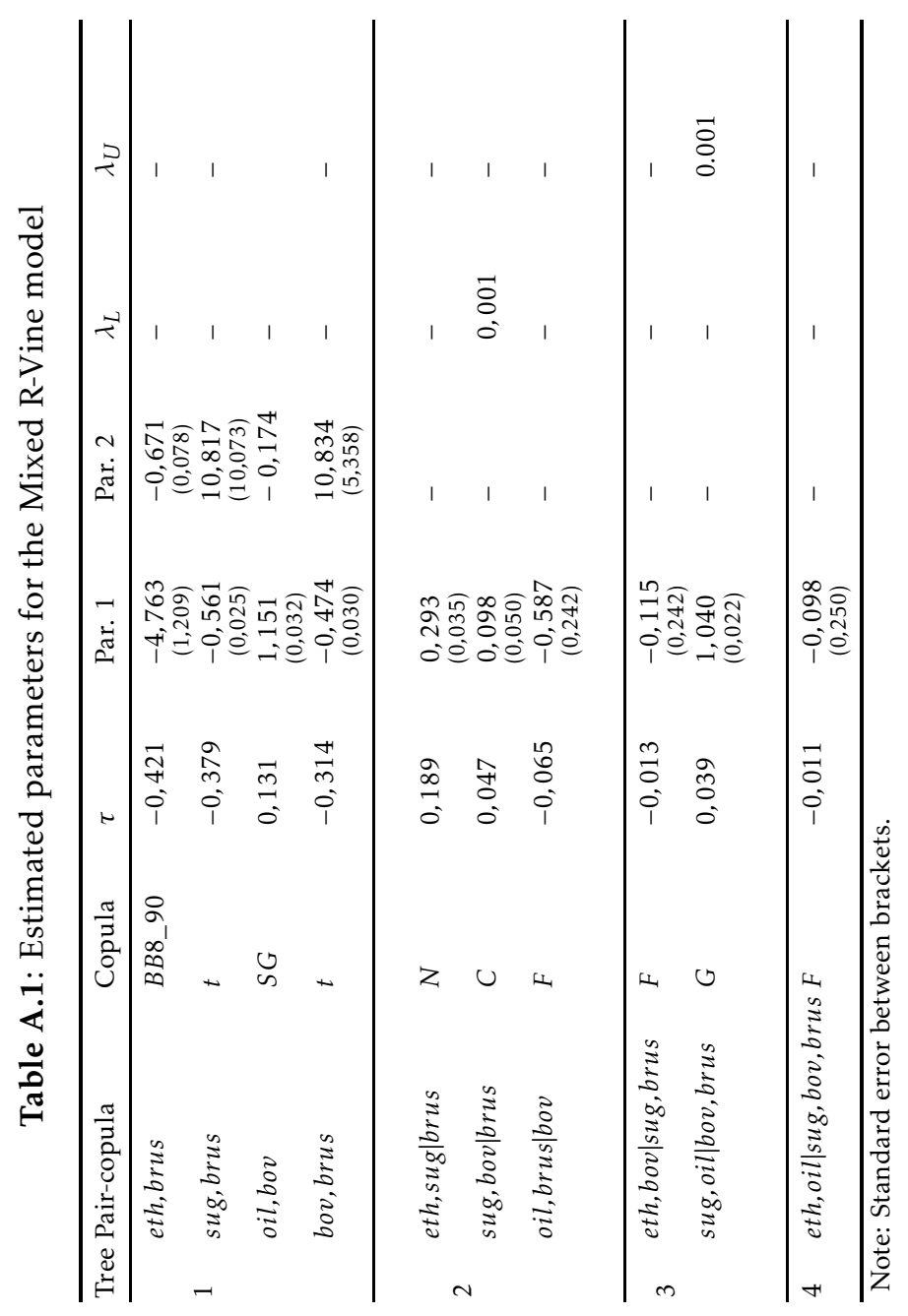


Table A.2: Estimated parameters for the Mixed C-Vine model

\begin{tabular}{|c|c|c|c|c|c|c|c|}
\hline \multicolumn{2}{|c|}{ Tree Pair-copula } & \multirow{2}{*}{$\frac{\text { Copula }}{\text { BB8_90 }}$} & \multirow{2}{*}{$\frac{\tau}{-0,421}$} & \multirow{2}{*}{$\begin{array}{c}\text { Par. 1 } \\
-4,763 \\
(1,208)\end{array}$} & \multirow{2}{*}{$\begin{array}{c}\text { Par. } 2 \\
-0,671 \\
(0,078)\end{array}$} & \multirow{2}{*}{$\frac{\lambda_{L}}{-}$} & \multirow{2}{*}{$\frac{\lambda_{U}}{-}$} \\
\hline \multirow{4}{*}{1} & eth,brus & & & & & & \\
\hline & oil,brus & $N$ & $-0,117$ & $\begin{array}{c}-0,182 \\
(0,037)\end{array}$ & - & - & - \\
\hline & sug,brus & $t$ & $-0,379$ & $\begin{array}{c}-0,561 \\
(0,025)\end{array}$ & $\begin{array}{c}10,817 \\
(8,746)\end{array}$ & - & - \\
\hline & bov,brus & $t$ & $-0,314$ & $\begin{array}{c}-0,474 \\
(0,029)\end{array}$ & $\begin{array}{c}10,834 \\
(6,796)\end{array}$ & - & - \\
\hline \multirow{3}{*}{2} & eth,sug|brus & $N$ & 0,189 & $\begin{array}{l}0,293 \\
(0,035)\end{array}$ & - & - & - \\
\hline & oil,sug|brus & G & 0,042 & $\begin{array}{l}1,044 \\
(0,024)\end{array}$ & - & - & 0,06 \\
\hline & bov,sug|brus & C & 0,047 & $\begin{array}{l}0,098 \\
(0,049)\end{array}$ & - & - & - \\
\hline \multirow[t]{2}{*}{3} & eth,oil|sug,brus & $F$ & $-0,014$ & $\begin{array}{c}-0,122 \\
(0,248)\end{array}$ & - & - & - \\
\hline & bov, oillsug,brus & $S B B 8$ & 0,098 & $\begin{array}{l}1,335 \\
(0,206)\end{array}$ & $\begin{array}{l}0,893 \\
(0,125)\end{array}$ & - & - \\
\hline 4 & \multicolumn{2}{|c|}{ eth,bov|oil,sug.brus C_270 } & $-0,010$ & $\begin{array}{c}-0,020 \\
(0,039)\end{array}$ & - & - & - \\
\hline
\end{tabular}

Note: Standard error between brackets.

Table A.3: Estimated parameters for the Mixed C-Vine model with independent terms

\begin{tabular}{|c|c|c|c|c|c|c|c|}
\hline \multicolumn{2}{|c|}{ Tree Pair-copula } & \multirow{2}{*}{$\frac{\text { Copula }}{\text { BB8_90 }}$} & \multirow{2}{*}{$\frac{\tau}{-0,421}$} & \multirow{2}{*}{$\begin{array}{c}\text { Par. 1 } \\
-4,763 \\
(1,208)\end{array}$} & \multirow{2}{*}{$\begin{array}{c}\text { Par. } 2 \\
-0,671 \\
(0,078)\end{array}$} & \multirow{2}{*}{$\frac{\lambda_{L}}{-}$} & \multirow{2}{*}{$\frac{\lambda_{L}}{-}$} \\
\hline \multirow{4}{*}{1} & eth,brus & & & & & & \\
\hline & oil,brus & $N$ & $-0,117$ & $\begin{array}{c}-0,182 \\
(0,038)\end{array}$ & - & - & - \\
\hline & sug,brus & $t$ & $-0,379$ & $\begin{array}{c}-0,561 \\
(0,025)\end{array}$ & $\begin{array}{c}10,817 \\
(7,132)\end{array}$ & - & - \\
\hline & bov,brus & $t$ & $-0,314$ & $\begin{array}{c}-0,474 \\
(0,029)\end{array}$ & $\begin{array}{c}10,834 \\
(5,924)\end{array}$ & - & - \\
\hline \multirow{3}{*}{2} & eth,sug|brus & $N$ & 0,189 & $\begin{array}{l}0,293 \\
(0,035)\end{array}$ & - & - & - \\
\hline & oil,sug|brus & $I$ & - & - & - & - & - \\
\hline & bov,sug|brus & C & 0,047 & $\begin{array}{l}0,098 \\
(0,048)\end{array}$ & - & 0,001 & - \\
\hline \multirow{2}{*}{3} & eth,oillsug,brus & $I$ & - & - & - & - & - \\
\hline & bov,oil|sug,brus & C & 0,087 & $\begin{array}{l}0,190 \\
(0,055)\end{array}$ & - & 0,026 & - \\
\hline 4 & \multicolumn{2}{|c|}{ eth,bov|oil,sug.brus I } & - & - & - & - & - \\
\hline
\end{tabular}

Note: Standard error between brackets. 
Table A.4: Estimated parameters for the Mixed R-Vine model with independent terms

\begin{tabular}{|c|c|c|c|c|c|c|c|}
\hline \multicolumn{2}{|c|}{ Tree Pair-copula } & \multirow{2}{*}{$\frac{\text { Copula }}{\text { BB8_90 }}$} & \multirow{2}{*}{$\frac{\tau}{-0,421}$} & \multirow{2}{*}{$\begin{array}{c}\text { Par. 1 } \\
-4,763 \\
(1,209)\end{array}$} & \multirow{2}{*}{$\begin{array}{c}\text { Par. 2 } \\
-0,671 \\
(0,078)\end{array}$} & \multirow{2}{*}{$\frac{\lambda_{L}}{-}$} & \multirow{2}{*}{$\lambda_{U}$} \\
\hline \multirow{4}{*}{1} & eth,brus & & & & & & \\
\hline & sug,brus & $t$ & $-0,379$ & $\begin{array}{c}-0,561 \\
(0,025)\end{array}$ & $\begin{array}{c}10,817 \\
(9,033)\end{array}$ & - & - \\
\hline & oil, bov & $S G$ & 0,131 & $\begin{array}{l}1,151 \\
(0,032)\end{array}$ & - & 0,174 & - \\
\hline & bov,brus & $t$ & $-0,314$ & $\begin{array}{c}-0,474 \\
(0,030)\end{array}$ & $\begin{array}{c}10,834 \\
(5,352)\end{array}$ & - & - \\
\hline \multirow[t]{3}{*}{2} & eth,sug|brus & $N$ & 0,189 & $\begin{array}{l}0,293 \\
(0,035)\end{array}$ & - & - & - \\
\hline & sug,bov|brus & C & 0,047 & $\begin{array}{l}0,098 \\
(0,049)\end{array}$ & - & 0,001 & - \\
\hline & oil,brus|bov & $F$ & $-0,065$ & $\begin{array}{c}-0,587 \\
(0,243)\end{array}$ & - & - & - \\
\hline
\end{tabular}

\begin{tabular}{lll}
\hline eth, bov|sug, brus & $I$ \\
sug, oil|bov, brus & $I$
\end{tabular}

4 eth,oil|sug,bov,brus I

Note: Standard errors between brackets.

Table A.5: Estimated parameters for the Mixed R-Vine Normal/Student-t

\begin{tabular}{|c|c|c|c|c|c|c|c|}
\hline \multicolumn{2}{|c|}{ Tree Pair-copula } & \multirow{2}{*}{$\begin{array}{l}\text { Copula } \\
t\end{array}$} & \multirow{2}{*}{$\begin{array}{l}\tau \\
-0,399\end{array}$} & \multirow{2}{*}{$\begin{array}{c}\text { Par. } 1 \\
\\
-0,586 \\
(0,027)\end{array}$} & \multirow{2}{*}{$\begin{array}{l}\text { Par. } 2 \\
3,943 \\
(0,714)\end{array}$} & \multirow{2}{*}{$\begin{array}{l}\lambda_{L} \\
0,008\end{array}$} & \multirow{2}{*}{$\begin{array}{l}\lambda_{U} \\
0,008\end{array}$} \\
\hline 1 & eth, brus & & & & & & \\
\hline & sug,brus & $t$ & $-0,379$ & $\begin{array}{c}-0,561 \\
(0,025)\end{array}$ & $\begin{array}{c}10,817 \\
(4,375)\end{array}$ & - & - \\
\hline & oil,bov & $t$ & 0,139 & $\begin{array}{l}0,217 \\
(0,040)\end{array}$ & $\begin{array}{l}8,626 \\
(3,597)\end{array}$ & 0,033 & 0,033 \\
\hline & bov,brus & $t$ & $-0,314$ & $\begin{array}{c}-0,474 \\
(0,030)\end{array}$ & $\begin{array}{c}10,834 \\
(5,402)\end{array}$ & - & - \\
\hline \multirow[t]{3}{*}{2} & eth,sug|brus & $N$ & 0,189 & $\begin{array}{l}0,292 \\
(0,034)\end{array}$ & - & - & - \\
\hline & sug,bov|brus & $N$ & 0,043 & $\begin{array}{l}0,068 \\
(0,039)\end{array}$ & - & - & - \\
\hline & oil,brus|bov & $N$ & $-0,060$ & $\begin{array}{c}-0,095 \\
(0,039)\end{array}$ & - & - & - \\
\hline \multirow[t]{2}{*}{3} & eth,bov|sug,brus & $N$ & $-0,002$ & $\begin{array}{c}-0,003 \\
(0,039)\end{array}$ & - & - & - \\
\hline & sug,oil|bov,brus & $t$ & 0,047 & $\begin{array}{l}0,073 \\
(0,041)\end{array}$ & $\begin{array}{l}19,714 \\
(13,971)\end{array}$ & - & - \\
\hline 4 & \multicolumn{2}{|c|}{ eth,oil|sug,bov,brus $N$} & 0,003 & $\begin{array}{l}0,004 \\
(0,039)\end{array}$ & - & - & - \\
\hline
\end{tabular}

Note: Standard error between brackets. 
Table A.6: Estimated parameters for the Mixed R-Vine Normal/Student-t with independent

\begin{tabular}{|c|c|c|c|c|c|c|c|}
\hline \multicolumn{2}{|c|}{ Tree Pair-copula } & Copula & $\tau$ & Par. 1 & Par. 2 & $\lambda_{L}$ & $\lambda_{U}$ \\
\hline 1 & eth, brus & $t$ & $-0,399$ & $\begin{array}{l}-0,586 \\
(0,027)\end{array}$ & $\begin{array}{l}3,943 \\
(0,714)\end{array}$ & 0,008 & 0,008 \\
\hline & sug,brus & $t$ & $-0,379$ & $\begin{array}{c}-0,561 \\
(0,025)\end{array}$ & $\begin{array}{c}10,817 \\
(4,661)\end{array}$ & - & - \\
\hline & oil,bov & $t$ & 0,139 & $\begin{array}{l}0,217 \\
(0,040)\end{array}$ & $\begin{array}{l}8,626 \\
(3,766)\end{array}$ & 0,033 & 0,033 \\
\hline & bov,brus & $t$ & $-0,314$ & $\begin{array}{c}-0,474 \\
(0,030)\end{array}$ & $\begin{array}{c}10,834 \\
(5,418)\end{array}$ & - & - \\
\hline \multirow[t]{3}{*}{2} & eth,sug|brus & $N$ & 0,189 & $\begin{array}{l}0,292 \\
(0,034)\end{array}$ & - & - & - \\
\hline & sug,bov|brus & $N$ & 0,043 & $\begin{array}{l}0,068 \\
(0,039)\end{array}$ & - & - & - \\
\hline & oil,brus|bov & $N$ & $-0,060$ & $\begin{array}{c}-0,095 \\
(0,039)\end{array}$ & - & - & - \\
\hline \multirow[t]{2}{*}{3} & eth, bov|sug,brus & $I$ & & & & & \\
\hline & sug,oil|bov,brus & $I$ & & & & & \\
\hline 4 & eth,oil|sug,bov, b & $I$ & & & & & \\
\hline
\end{tabular}

Note: Standard error between brackets.

Table A.7: Estimated parameters for the Mixed C-Vine with independent terms

\begin{tabular}{|c|c|c|c|c|c|c|c|}
\hline \multicolumn{2}{|c|}{ Tree Pair-copula } & \multirow{2}{*}{$\begin{array}{l}\text { Copula } \\
\text { BB8_90 }\end{array}$} & \multirow{2}{*}{$\begin{array}{l}\tau \\
-0,421\end{array}$} & \multirow{2}{*}{$\begin{array}{c}\text { Par. } 1 \\
-4,763 \\
(1,208)\end{array}$} & \multirow{2}{*}{$\begin{array}{c}\text { Par. } 2 \\
-0,671 \\
(0,078)\end{array}$} & \multirow{2}{*}{$\lambda_{L}$} & \multirow{2}{*}{$\lambda_{U}$} \\
\hline 1 & eth,brus & & & & & & \\
\hline & oil,brus & $N$ & $-0,117$ & $\begin{array}{c}-0,182 \\
(0,038)\end{array}$ & - & - & - \\
\hline & sug,brus & $t$ & $-0,379$ & $\begin{array}{c}-0,561 \\
(0,025)\end{array}$ & $\begin{array}{r}10,817 \\
(7,132)\end{array}$ & - & - \\
\hline & bov,brus & $t$ & $-0,314$ & $\begin{array}{c}-0,474 \\
(0,029)\end{array}$ & $\begin{array}{c}10,834 \\
(5,924)\end{array}$ & - & - \\
\hline \multirow[t]{3}{*}{2} & eth,sug|brus & $N$ & 0,189 & $\begin{array}{l}0,293 \\
(0,035)\end{array}$ & - & - & - \\
\hline & oil,sug|brus & $I$ & - & - & - & - & - \\
\hline & bov,sug|brus & C & 0,047 & $\begin{array}{l}0,098 \\
(0,048)\end{array}$ & - & 0,001 & - \\
\hline \multirow[t]{2}{*}{3} & eth,oil|sug,brus & $I$ & - & - & - & - & - \\
\hline & bov,oil|sug,brus & $C$ & 0,087 & $\begin{array}{l}0,190 \\
(0,055)\end{array}$ & - & 0,026 & - \\
\hline 4 & \multicolumn{7}{|c|}{ eth,bov|oil,sug,brus } \\
\hline
\end{tabular}

